Orthopaedics

\section{Painful knee}

\section{K Selvarajan, R Vadivelu, T P Green}

\begin{abstract}
A 26 year old Brazilian woman presented with a four year history of a painful left knee. The pain started as a dull ache, but it gradually got worse and became constant. Over the previous few months, she noticed an intermittent swelling on the lateral aspect of her left knee. The pain and swelling was aggravated by routine household work and walking for a short distance. Rest and analgesia eased her pain in the knee. She had no history of trauma or fever or hyperlaxity of her joints or of locking or giving way; she also had no family history suggestive of joint disorders.

On clinical examination, she had a small swelling on the lateral aspect of her left knee, which became prominent on flexion. She was slightly tender along the lateral joint line. She had full range
\end{abstract}

of movements in her affected knee and it was fully stable in all directions. Her baseline blood investigations, for example, full blood count, inflammatory markers, and plain radiography of the knee were normal. Magnetic resonance imaging (MRI) of her knee is shown in fig 1 .

\section{QUESTIONS}

(1) What are features seen on MRI?

(2) What are the differential diagnoses?

(3) What is the diagnosis?

(4) What is the frequently associated finding with this condition?

(5) How should the condition be managed?

Postgrad Med J 2004;80:556.

doi: 10.1136/pgmi.2003.011411

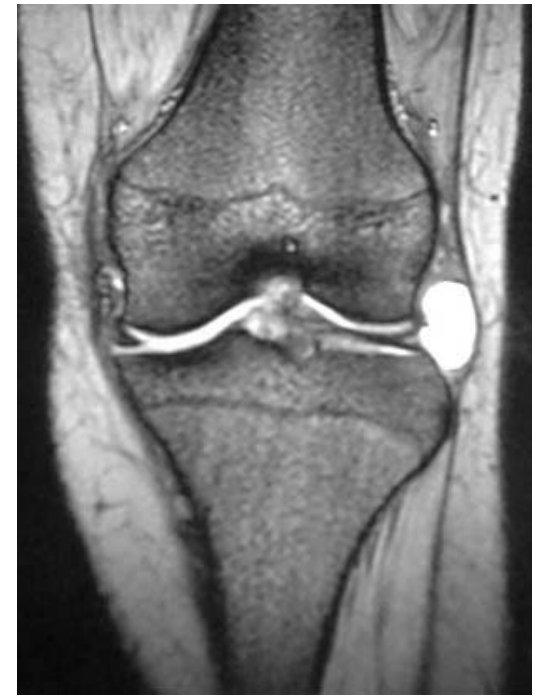

Figure 1 MRI of patient's knee.

..............

\section{Authors' affiliations}

K Selvarajan, R Vadivelu, T P Green,

Department of Orthopaedics, Leicester

General Hospital, Leicester, UK

Correspondence to: Mr Vadivelu, rvadivelu@ yahoo.com

Submitted 18 June 2003

Accepted 25 September 2003 